\title{
Performance Evaluation of Automated Algorithm for Breast Cancer Cell Counting
}

\author{
C. Primkhajeepong, P. Phukpattaranont, S. Limsiroratana, P. Boonyaphiphat and K. Kayasut
}

\begin{abstract}
This paper presents an automated algorithm for breast cancer cell counting and its performance. The algorithm for analyzing stained breast cancer cell image consists of four procedures, i.e. image preprocessing, segmentation, feature extraction, and classification. In the image preprocessing, the wavelet transform is performed. The global thresholding and morphological operations are performed in segmentation. In the feature extraction, the average of $b^{*}$ in CIE $L * a * b *$ color space is extracted. The segmented cells are classified by using extracted feature. If the average of $b^{*}$ is positive, the cancer cell is positive cell. In addition, if the average of $b$ * is negative, the cancer cell is negative cell. The segmentation results show that the average performance is $85 \%$ when square-shaped structuring element and city block distance transform are used. The classification results show that the average performance is $94 \%$.
\end{abstract}

Index Terms-Biomedical Image Processing, Quantitative Immunohistophathology, Wavelet Transform, Segmentation, Morphological Operation.

\section{INTRODUCTION}

Breast cancer is the most common cancer in female worldwide [1]. In the pathological analysis of the breast cancer, the suspect tissue biopsy or fine needle aspiration is first analyzed by the pathologist visualization. If the cancer is beginning from the duct, estrogen receptor (ER) is stained by using immunohistochemistry (IHC). Immunohistochemistry is a technique used for detecting in situ a tissue antigen by a specific antibody. An antigen-antibody reaction is visualized by the color development of specific dye and can be seen by light microscope. The tissue antigen is presented at any part of the cell, i.e., cell membrane, cytoplasm or nucleus.

Manuscript received November 8, 2009. This work was supported in part by the Department of Electrical Engineering, Department of Computer Engineering, Faculty of Engineering under Grant ENG-51-2-7-02-0018-S, Department of pathology, Faculty of Medicine, and Graduate School, Prince of Songkla University.

C. Primkhajeepong is with the Department of Electrical Engineering, Faculty of Engineering. Prince of Songkla University, Songkhla, Thailand (e-mail: chalit.pr@gmail.com).

P. Phukpattaranont is with the Department of Electrical Engineering, Faculty of Engineering. Prince of Songkla University, Songkhla, Thailand (e-mail: pronchai.ph@gmail.com).

S. Limsiroratana is with the Department of Computer Engineering, Faculty of Engineering. Prince of Songkla University, Songkhla, Thailand (e-mail: somchai@coe.psu.ac.th).

P. Boonyaphiphat is with the Department of Pathology, Faculty of Medicine, Prince of Songkla University, Songkhla, Thailand (e-mail: pleamjit.b@psu.ac.th).

K. Kayasut is with the Department of Pathology, Faculty of Medicine, Prince of Songkla University, Songkhla, Thailand (e-mail: K_kanita@hotmail.com).
Therefore, it is a useful technique to demonstrate the protein markers including cancer cell. Estrogen receptor (ER) is prognostic marker for breast cancer detected by this method. Traditionally, the percentage of positive cells of those markers is semi-quantitatively counted. However, it is time consuming, costly, subjective and tedious. In order to overcome these problems, a computer-aided system of image analysis that previously requires manual operations is performed on the basis of the developments in computer capabilities and image processing algorithms [2]-[4].

There are a number of benefits that result from a computer-aided analysis. These include an acceleration of the process, a reduction in cost for image analysis, as well as a decrement in a false inspection due to fatigue. Additionally, the automated analysis provides a quantitative description. Based on this quantitative measurement, the analysis result is objective. Furthermore, the correlation of the quantitative categorization with patient symptoms may allow for an automated diagnostic system [5]. However, it is not expected that computer-aided image analysis will replace pathologist's experience. It is only an aid to the pathologist for the repeated routine work and yields quantitative results that complement and enhance interpretations by pathologists. Visual examination by the pathologist is still required where unusual or abnormal cells that the method is not trained to deal with are encountered.

Previously, evaluation of ER in breast cancer cell image is analyzed by using Photoshop (Adobe Systems Inc., USA) [6], [7] and WinROOF (Mitani Co., Ltd., Japan) [8] which are the commercial software. They are costly, not automatic analysis, and not specific software for breast cancer cell image analysis. Subsequently, the automatic algorithm is developed to analyze the cancer cell image by using the image processing algorithms. Liu et al. presented the microscopic image analysis algorithm consisting of adaptive threshold segmentation based on the RGB and HIS color spaces, feature extraction using canny operator and eight-chain code tracking, and classification using morphological operations and colourometry. It can efficiently segment cell image and receive high accuracy of cancer cell diagnosis [9]. Phukpattaranont et al. presented the evaluation of computer-aided analysis for nuclear stained breast cancer cell images. The algorithm for image analysis consists of segmentation using neural network and mathematical morphology, feature consisting of average value of $L^{*}, a^{*}, b^{*}$ of each cell are extracted, and classification using Euclidian distance in CIE $L^{*} a^{*} b^{*}$ color space. However, the segmentation procedure is not automatic. Furthermore, there is the comparison of algorithm results with the expert as a 
performance evaluation [10]. From above researches, the algorithm for breast cancer cell

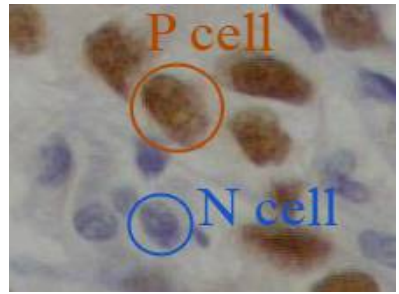

Fig. 1 An example of stained cancer cell image.

image analysis should automatically analyze the image and should have comparison of the results with the expert to evaluate the performance.

In this paper we present an automated algorithm for breast cancer cell counting and its performance evaluation compared with an expert. The algorithm consists of image preprocessing using wavelet transform, segmentation using global thresholding and morphological operations, feature, i.e. average value of $b^{*}$ of each cell is extracted, and classification using the extracted feature.

\section{BREAST CANCER CELl IMAGES}

Fig. 1 shows an example of stained cancer cell image from microscope. The stained cancer cells are classified into two categories according to their nuclei color contents, i.e. brown and blue. The brown and blue colors indicate the positive (P) and negative $(\mathrm{N})$ results, respectively. In other words, the brown cells have estrogen receptor whereas the blue cells do not have the estrogen receptor in the nucleus of cancer cell. The ratio of the total positive cells $(\mathrm{P})$ and the total number of cancer cells $(\mathrm{P}+\mathrm{N})$ in the whole image is used by a doctor for medical planning and treatment.

The images used in this paper were cancer tissue stained with the antibody to ER in the nuclei. The tissue sections were observed under a microscope with a magnifying factor of 40x. The contrast and intensity of staining were manually corrected in such a way that the digitized image became visually acceptable for further manual classification by a specialist. The twenty two of cancer cell images were acquired in color using the Eclipse 80i advanced research microscope (Nikon Instech Co., Ltd., Japan). The digital images were saved as a 24-bits color JPEG file with $512 \times 640$ pixels in size.

\section{CANCER Cell Image ANalysis}

Fig. 2 shows the procedures of the algorithm for automatic cancer cell image analysis, i.e. the image preprocessing, segmentation, feature extraction and classification. Details of each procedure are given below.

\section{A. Image preprocessing}

In the image preprocessing, the wavelet transform (WT) is performed. The WT is applied with the original image. In this work, we use the Haar wavelet because it is the simplest possible wavelet. The Haar wavelet function $\psi(x)$ and scaling function $\varphi(x)$ can be described as [11]

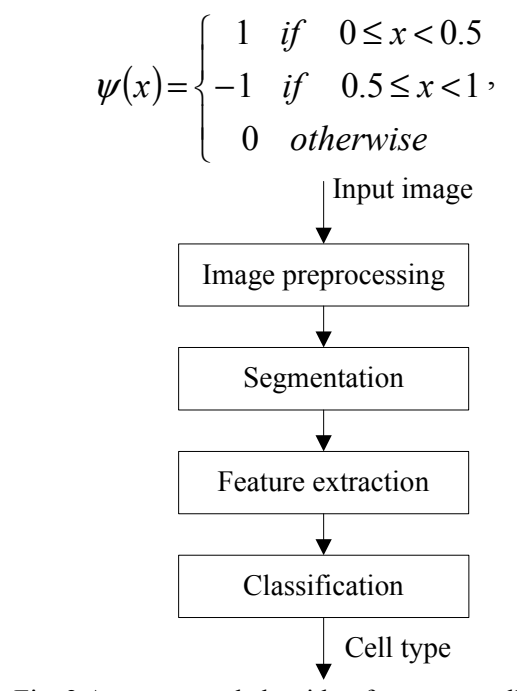

Fig. 2 An automated algorithm for cancer cell counting.

$$
\varphi(x)=\left\{\begin{array}{ll}
1 & \text { if } \quad 0 \leq x<1 \\
0 & \text { otherwise }
\end{array} .\right.
$$

By using WT, the original image is passed through low-pass and high-pass filters to generate low-low (LL), low-high (LH), high-low (HL), and high-high (HH) sub-bands [12], [13]. The LL sub-band image is used for next procedure.

\section{B. Segmentation}

In the segmentation, the global thresholding and morphological operations are performed. The details of each stage are given below.

1) Global Thresholding

The RGB image from WT stage is converted to gray-scale image. The conversion of RGB image to gray-scale image can be expressed as [14]

$$
\text { Gray }=(0.299 \times R)+(0.587 \times G)+(0.114 \times B),
$$

where Gray is gray-scale image and $R, G, B$ are red, green, blue components, respectively. Next, the gray-scale image is performed by using the global thresholding. It is defined by [15]

$$
g(x, y)=\left\{\begin{array}{ll}
1, & f(x, y)>T \\
0 & , \quad f(x, y) \leq T
\end{array},\right.
$$

where $g(x, y)$ is the threshold image, $f(x, y)$ is the gray-level value at $(x, y)$ pixel, and $T$ is the threshold value from Otsu's method [16].

2) Morphological Operations

After finishing the global thresholding that generates the black and white (BW) image, the morphological operations, i.e. the opening, region filling, border clearing, and watershed segmentation are performed.

-The opening is used to remove large and small objects that are not cancer cell. The morphological opening is performed with structure element [17]. Moreover, the morphological area opening is performed to remove the objects that are higher than 450 pixels and lower than 40 pixels.

- The region filling is performed to fill the cell regions and holes by using morphological reconstruction [17].

- The border clearing is performed to remove the imperfect cell on the image border by using morphological 

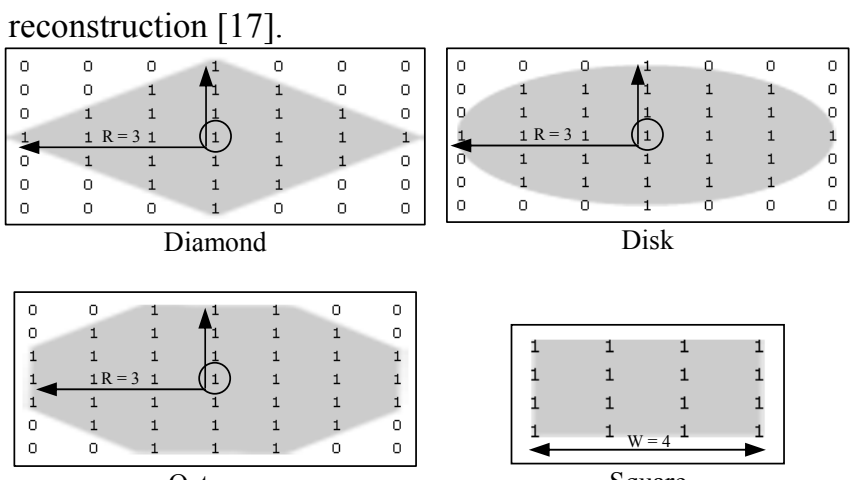

Octagon

Fig. 3 Structuring elements.

-The watershed segmentation is a segmentation technique used to divide the overlapping cells [18]. It uses the Fernand Meyer's algorithm [19] with distance transform [20].

In this procedure, the shape of structuring elements (i.e. diamond, disk, octagon, and square) and the form of distance transform (i.e. euclidean, chessboard, cityblock, and quasi-euclidean) are compared to determine the highest performance. The shape and size of structuring elements are shown in Fig. 3. The form of distance transform is shown in Fig. 4 and its function can be defined by [21]

$$
\begin{aligned}
& d_{\text {euclidean }}=\sqrt{\left(x_{1}-x_{2}\right)^{2}+\left(y_{1}-y_{2}\right)^{2}}, \\
& d_{\text {chessboard }}=\max \left(\left|x_{1}-x_{2}\right|,\left|y_{1}-y_{2}\right|\right), \\
& d_{\text {cityblock }}=\left|x_{1}-x_{2}\right|+\left|y_{1}-y_{2}\right|, \\
& d_{\text {quasi-euclidean }}=\left\{\begin{array}{c}
\left|x_{1}-x_{2}\right|+(\sqrt{2}-1)\left|y_{1}-y_{2}\right| \\
, \quad \text { if }\left|x_{1}-x_{2}\right|>\left|y_{1}-y_{2}\right| \\
(\sqrt{2}-1)\left|x_{1}-x_{2}\right|+\left|y_{1}-y_{2}\right|
\end{array},\right. \\
& , \quad \text { otherwise }
\end{aligned}
$$

where $d_{\text {euclidean }}, d_{\text {chessboard }}, d_{\text {cityblock }}$, and $d_{\text {quasi-euclidean }}$ are the distance between pixel $\left(x_{1}, y_{1}\right)$ and $\left(x_{2}, y_{2}\right)$ in euclidean, chessboard, city block, and quasi-euclidean, respectively.

\section{Feature Extraction}

After all cancer cells in the image are successfully segmented, we compute the feature of each isolated cancer cell, i.e., the average values of $b^{*}$ of CIE $L^{*} a^{*} b^{*}$. The CIE $L * a * b *$ color space can be defined by $[10]$

$$
\begin{aligned}
& L^{*}=116\left(Y / Y_{n}\right)^{1 / 3}-16, \\
& a^{*}=500\left[\left(X / X_{n}\right)^{1 / 3}-\left(Y / Y_{n}\right)^{1 / 3}\right], \\
& b^{*}=200\left[\left(Y / Y_{n}\right)^{1 / 3}-\left(Z / Z_{n}\right)^{1 / 3}\right],
\end{aligned}
$$

for $X / X_{n}, Y / Y_{n}, Z / Z_{n}>0.01$. The values $X_{n}, Y_{n}, Z_{n}$ are the CIE
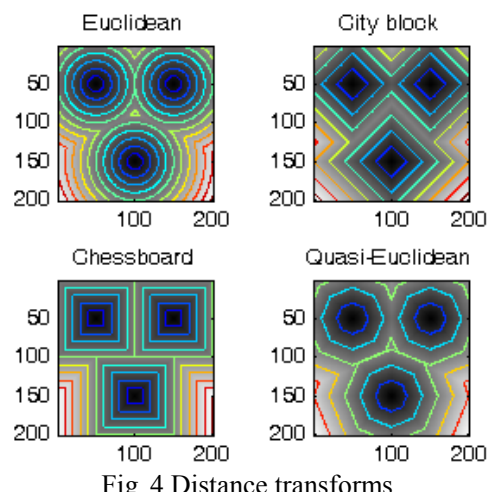

Fig. 4 Distance transforms.

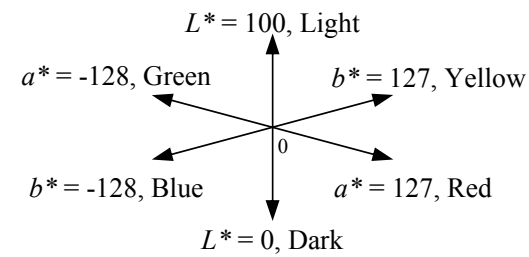

Fig. 5 A three-dimensional representation of CIE $L * a * b *$ color space [10].

(Commission International de l'Eclairage) tristimulus values of the reference white under the reference illumination, and $X, Y, Z$ are the tristimulus values, which are mapped to the CIE color space. The $L^{*}$ component represents intensity, which is the measure of brightness. $L^{*}=0$ yields black and $L^{*}=100$ indicates white. The values of $a^{*}$ and $b^{*}$ are in the range from -128 to 127 . The $a^{*}$ and $b^{*}$ values are proportional to red-green and yellow-blue color contents, respectively. That is, for $a^{*}$ negative values indicate green whereas positive values indicate red. For $b^{*}$, negative values indicate blue and positive values indicate yellow. A three-dimensional representation of CIELab color space is shown in Fig 5.

The average value of $b^{*}$ of each isolated cancer cell can be defined by

$$
\overline{b_{i}^{*}}=\left[\left(\sum x\right)_{i} / n_{i}\right]-127,
$$

where $\overline{b_{i}^{*}}$ is the average value of $b^{*}$ of the ith isolated cancer cell, $\left(\sum x\right)_{i}$ is the summary of pixel value in the $i$ th isolated cancer cell, $n_{i}$ is the area of the $i$ th isolated cancer cell, and 127 is the normalization value.

\section{Classification}

In this procedure, the feature based on color contents to classify cancer cells is used. The $\mathrm{P}$ cell is brown which consists of yellow content and the $\mathrm{N}$ cell is blue which consists of blue content. If the average of $b^{*}$ is positive, the cancer cell is $\mathrm{P}$ cell. In addition, if the average of $b^{*}$ is negative, the cancer cell is $\mathrm{N}$ cell. The cancer cell classification can be defined by

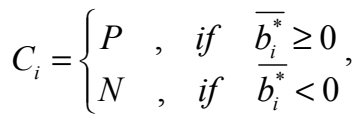

where $C_{i}$ is the type of cancer cell, $P$ is the positive cell, $N$ is the negative, and $\overline{b_{i}^{*}}$ is the average value of $b^{*}$ of the $i$ th isolated cancer cell. 


\section{Performance Evaluation}

Two measures were defined in order to evaluate the performance of the algorithm in segmentation of nuclei from background. Sensitivity $(S S 1)$ is the probability that a nucleus will be detected in case it has been marked by the experts. It can be expressed as

$$
S S 1=\frac{T P 1}{T P 1+F N 1}
$$

where TP1 (true positive) are the number of nuclei which have been marked by the experts and also detected by the algorithm and FN1 (false negative) are the number of nuclei which are marked by the experts but are not detected by the algorithm. Positive predictive value $(P P V 1)$ is the probability that the detection of a nucleus is actually associated with a nucleus marked by the experts. It can be expressed as

$$
P P V 1=\frac{T P 1}{T P 1+F P 1},
$$

where $F P 1$ (false positive) are the number of nuclei which are not marked by the exports but are detected by the algorithm.

In addition, there are four measures were defined in order to evaluate the performance of the algorithm for nucleus color classification after nuclei were segmented. Sensitivity $(S S 2)$ is the probability that a $\mathrm{P}$ nucleus will be detected in case it has been marked positive by the experts. Positive predictive value $(P P V 2)$ is the probability that the detection of a $\mathrm{P}$ nucleus is actually associated with a $\mathrm{P}$ nucleus marked by the experts. Specificity $(S C 2)$ is the probability that a $\mathrm{N}$ nucleus will be detected in case it has been marked negative by the experts. Negative predictive value $(N P V 2)$ is the probability that the detection of an $\mathrm{N}$ nucleus is actually associated with an $\mathrm{N}$ nucleus marked by the experts. The $S S 2, P P V 2, S C 2$, and $N P V 2$ can be expressed as

$$
\begin{aligned}
& S S 2=\frac{T P 2}{T P 2+F N 2}, \\
& P P V 2=\frac{T P 2}{T P 2+F P 2}, \\
& S C 2=\frac{T N 2}{T N 2+F P 2}, \\
& N P V 2=\frac{T N 2}{T N 2+F N 2},
\end{aligned}
$$

where TP2 (true positive) are the number of nuclei which the experts and the algorithm mark to P cells, TN2 (true negative) are the number of nuclei which the experts and the algorithm mark to N cells, FP2 (false positive) are the number of nuclei which the experts mark to $\mathrm{N}$ cells but the algorithm mark to $\mathrm{P}$ cells, and FN2 (false negative) are the number of nuclei which the experts mark to $\mathrm{P}$ cells but the algorithm mark to $\mathrm{N}$ cells [10].

\section{RESUltS AND DisCUSSION}

Fig. 6(a) is the example of original image with $512 \times 640$ pixels in size. In the image preprocessing, the WT is performed. The LL sub-band image from WT is shown in Fig. 6 (b). The size of image from WT is reduced to $256 \times 320$ pixels. In the segmentation, the WT image in RGB is converted to gray-scale color space as shown in Fig. 6(c). The global thresholding is performed on gray-scale image. The threshold value from Otsu's method of this image is 120 . The threshold result is BW image as shown in Fig. 6(d). Next, the morphological operations, i.e. opening with square-shaped structuring element, region filling, border clearing, and watershed segmentation with city block distance transform are performed to remove the large and small objects that are not cells, fill the cell regions and holes, remove the imperfect cell in the image border, and segment the overlapping cells, respectively. The result from this procedure is shown in Fig. 6(e). The comparison of the segmented result by the algorithm marked with contour lines and the expert marked with the rectangular windows is shown in Fig. 6(f).

After all cancer cells are successfully segmented, the feature extraction will be performed. The WT image in RGB is converted to CIE $L^{*} a^{*} b^{*}$ color space consisting of $L^{*}, a^{*}$, and $b^{*}$. Fig. 7(a) shows scatter plot of the average value of $a^{*}$ and $b^{*}$ of each isolated cell. The cancer cells are divided into 2 groups using the average value of $b^{*}$. In the classification, the cancer cells are classified to $\mathrm{P}$ and $\mathrm{N}$ cells by using the extracted feature. If the average value of $b^{*}$ is positive, the cancer cell is $\mathrm{P}$ cell. In addition, if the average value of $b^{*}$ is negative, the cancer cell is $\mathrm{N}$ cell. Fig. 7(b) shows the comparison of the classified result by the algorithm (P and $\mathrm{N}$ cells marked with green and red contour lines, respectively) and the expert ( $\mathrm{P}$ and $\mathrm{N}$ cells marked with green and red rectangular windows, respectively).

The performance of the cancer cells segmentation of all 22 images is shown in Table 1. The segmenting result from the algorithm is almost accurately comparing with the expert. The maximum performance can be obtained using square-shaped structuring element and city-block distance transform. Its $S S 1$ and $P P V 1$ are $87 \pm 5 \%$ and $83 \pm 6 \%$, respectively. In addition, the performance of the cancer cells classification is shown in Table 2 . The average value of $S S 2$, $P P V 2, S C 2$, and NPV2 are $98 \pm 3 \%, 100 \pm 1 \%, 93 \pm 14 \%$, and $86 \pm 21 \%$, respectively.

\section{CONCLuSions}

This paper presents an automated algorithm for breast cancer cell counting and its performance evaluation. The algorithm procedure consists of image preprocessing, segmentation, feature extraction, and classification. The segmentation results show that the best average performance of the segmentation is $85 \%$ when square-shaped structuring element with four pixels in size, and city block distance transform are used. The classification results show that the average performance is $94 \%$. That is, the extracted feature, i.e. the average value of $b^{*}$ in CIE $L^{*} a^{*} b^{*}$, can accurately classify the cancer cells to $\mathrm{P}$ and $\mathrm{N}$ cells very well. 


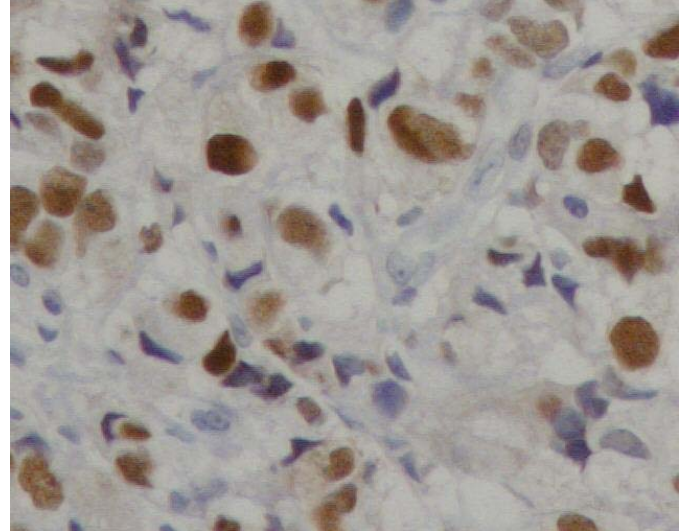

(a)

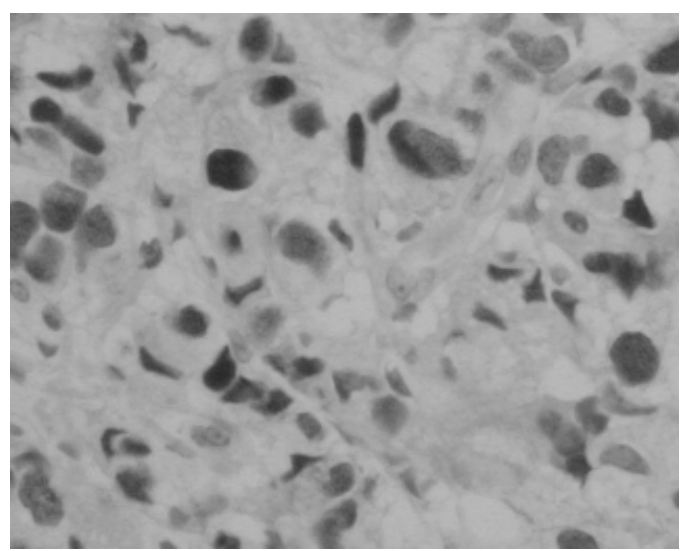

(c)

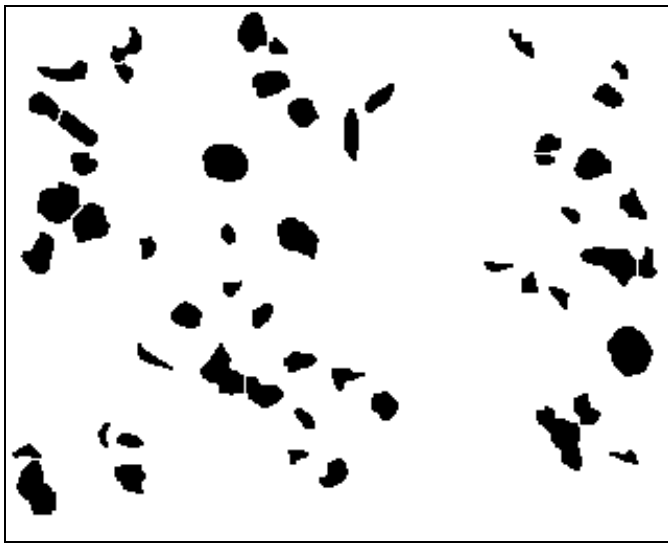

(e)

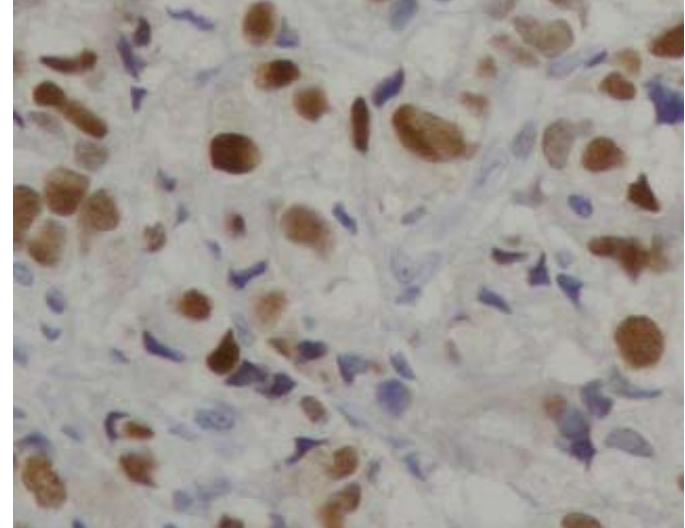

(b)

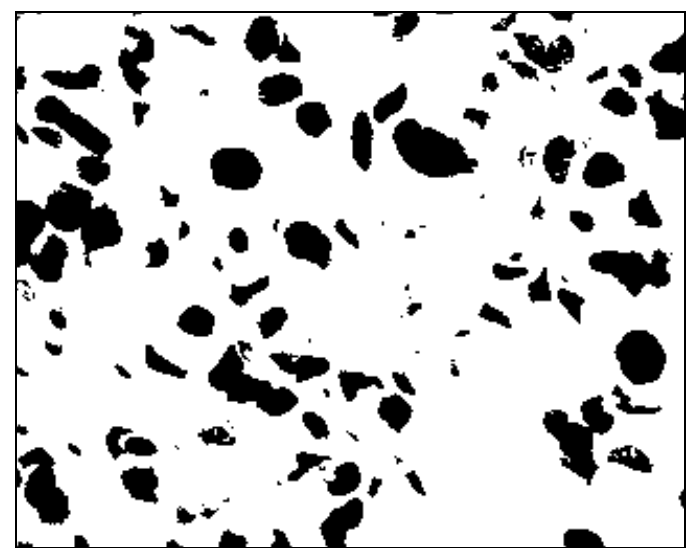

(d)

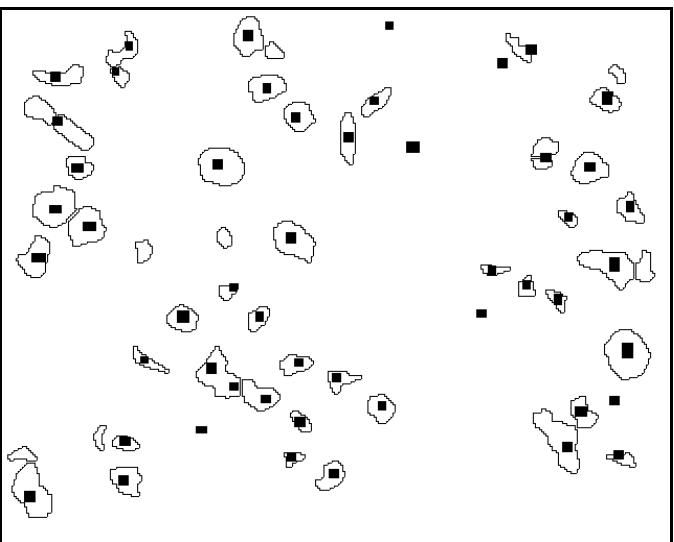

(f)

Fig. 6 (a) Cancer cell image No.10,(b) the result of WT, (c) the gray-scale image converted from WT image, (d) the BW image from using global thresholding, (e) the result from using morphological operations, and (f) segmented result (contour lines) compared with the expert (rectangular windows).

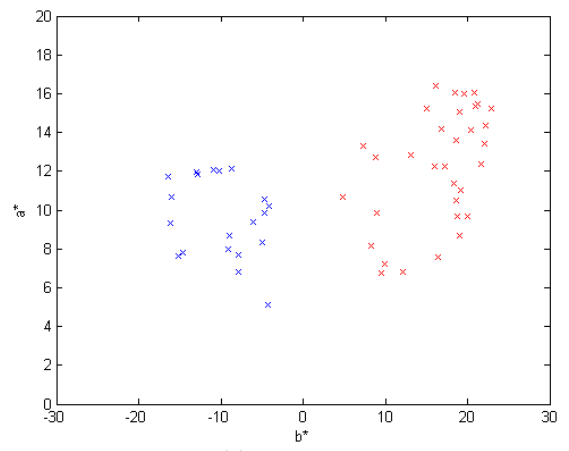

(a)

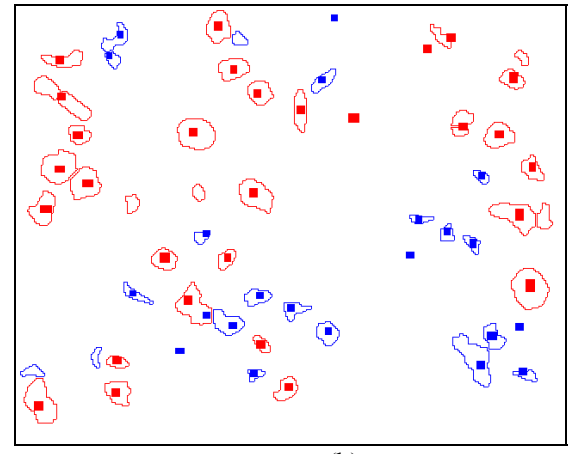

(b)

Fig. 7 (a) Scatter plot between average value of $a^{*}$ and $b^{*}$ of each isolated cell, and (b) comparison of the classified results by the algorithm (P and $\mathrm{N}$ cells marked with red and blue contour lines, respectively) and the expert ( $\mathrm{P}$ and $\mathrm{N}$ cells marked with red and blue rectangular windows, respectively). 
TABle 1 The Average Performance of the Cancer Cell SEGMENTATION

\begin{tabular}{|c|c|c|c|}
\hline $\begin{array}{c}\text { Structuring } \\
\text { element }\end{array}$ & $\begin{array}{c}\text { Distance } \\
\text { transform }\end{array}$ & SS1 (\%) & PPV1 (\%) \\
\hline \multirow{4}{*}{ Diamond } & Euclidean & $83 \pm 6$ & $76 \pm 7$ \\
\cline { 2 - 4 } & City block & $82 \pm 6$ & $83 \pm 5$ \\
\cline { 2 - 4 } & Chessboard & $82 \pm 6$ & $87 \pm 6$ \\
\cline { 2 - 4 } & Quasi-euclidean & $83 \pm 6$ & $76 \pm 6$ \\
\hline \multirow{4}{*}{ Disk } & Euclidean & $86 \pm 6$ & $74 \pm 5$ \\
\cline { 2 - 4 } & City block & $85 \pm 6$ & $84 \pm 6$ \\
\cline { 2 - 4 } & Chessboard & $84 \pm 6$ & $82 \pm 7$ \\
\cline { 2 - 4 } & Quasi-euclidean & $86 \pm 6$ & $75 \pm 6$ \\
\hline \multirow{4}{*}{ Octagon } & Euclidean & $84 \pm 7$ & $75 \pm 7$ \\
\cline { 2 - 4 } & City block & $83 \pm 6$ & $85 \pm 6$ \\
\cline { 2 - 4 } & Chessboard & $83 \pm 6$ & $86 \pm 6$ \\
\cline { 2 - 4 } & Quasi-euclidean & $84 \pm 7$ & $76 \pm 7$ \\
\hline \multirow{4}{*}{ Square } & Euclidean & $87 \pm 6$ & $73 \pm 6$ \\
\cline { 2 - 4 } & City block & $87 \pm 5$ & $83 \pm 6$ \\
\cline { 2 - 4 } & Chessboard & $86 \pm 6$ & $81 \pm 7$ \\
\cline { 2 - 4 } & Quasi-euclidean & $87 \pm 6$ & $73 \pm 7$ \\
\hline
\end{tabular}

TABLE 2 Performance of THe CANCER Cell Classification

\begin{tabular}{|c|c|c|c|}
\hline SS2 (\%) & $\boldsymbol{P P V 2}(\%)$ & $\boldsymbol{S C 2}(\mathbf{\%})$ & $\boldsymbol{N P V 2} \mathbf{( \% )}$ \\
\hline $98 \pm 3$ & $100 \pm 1$ & $93 \pm 14$ & $85 \pm 21$ \\
\hline
\end{tabular}

\section{ACKNOWLEDGMENT}

This research is supported by Department of Electrical Engineering, Department of Computer Engineering, Faculty of Engineering through contract no. ENG-51-2-7-02-0018-S, Department of pathology, Faculty of Medicine, and Graduate School, Prince of Songkla University.

\section{REFERENCES}

[1] A. Chaiwerawatana, "Breast," Cancer in Thailand, vol. 4, 1998-2000, pp. 48.

[2] J. P. Thiran and B. Macq, "Morphological Feature Extraction for the Classification of Digital Images of Cancerous Tissues," IEEE Trans. Biomed. Eng., vol. 43, no. 10, Oct. 1996, pp. 1011-1020.

[3] B. Fang, W. Hsu, and M. L. Lee, "On the Accurate Counting of Tumor Cells," IEEE Trans. Nanobiosci, vol.2, no. 2, June 2003, pp. 94-103.

[4] S. Petushi, C. Katsinis, C. Coward, F. Garcia, and A. Tozeren, "Automated Identification of Microstructures on Histology Slides," in IEEE International Symposium on Biomedical Imaging: Macro to Nano, vol. 1, 15-18 April 2004, pp. 424-427.

[5] L. O'Gorman, A. C. Sanderson, and K. Preston, "A System for Automated Liver Tissue Image Analysis: Methods and Results," IEEE Trans. Biomed. Eng., vol. 32, no. 9, Sept. 1985, pp. 696-706.

[6] H. A. Lehr, D. A. Mankoff, D. Corwin, G. Santeusanio, and A. M. Gown, "Application of Photoshop-based image analysis to quantification of hormone receptor expression in breast cancer," The Journal of Histochemistry and Cytochemistry, vol. 45, no. 11, Nov. 1997, 1559-1565.

[7] R. Mofidi, R. Walsh, P. F. Ridgway, T. Crotty, E. W. McDermott, T. V. Keavny, M. J. Duffy, A. D. K. Hill, and N. O'Higgins, "Objective measurement of breast cancer oestrogen receptor status through digital image analysis," Europeon Journal of Surgical Oncology, vol. 29, pp. 20-24.

[8] Y. Hatanaka, K. Hashizume, K. Nitta, T. Kato, L. Itoh, and Y. Tani, "Cytometrical image analysis for immunohistochemical hormone receptor status in breast carcinomas." Pathology International, vol. 53, no. 10 , Oct. 2003 , pp. 693-699.

[9] B. Liu, C. Yin, Z. Liu, Z. Zhang, J. Gao, M. Zhu, J. Gu, and K. Xu, "Microscopic image analysis and recognition on pathological cells," in Electrical and Computer Engineering, Canadian Conference on, 22-26 April 2007, pp. 1022-1025.

[10] P. Phukpattaranont, S. Limsiroratana, and P. Boonyaphiphat, "Evaluation of computer-aided analysis for nuclear stained breast cancer cell images," in The 3rd International Symposium on Biomedical Engineering, 10-11 Nov. 2008, pp. 213-216.
[11] M. Misiti, Y. Misiti, G. Oppenheim, and J. M. Poggi, Wavelet ToolboxTM 4 User's Guide, MA: The MathWorks, Inc., 2007.

[12] I. S. Koko and H. Agustiawan, "Two-dimentional Discrete Wavelet Transform Memory Architechure," International Journal of Computer and Electrical Engineering, vol. 1, no. 1, April 2009, pp. 84-97.

[13] P.R. Reddy, V.N.K. Prasad, and S. Rao, "Robust Digital Watermarking of Image using Wavelets," International Journal of Computer and Electrical Engineering, vol. 1, no. 2, June 2009, pp. 111-116.

[14] A. McAndrew, Introduction to Digital Image Processing with MATLAB, MA: Thomson Learning, Inc., 2004.

[15] G. J. Awcock, and R. Thomas, Applied Image Processing, NJ: McGraw-Hill, Inc., 1995.

[16] N. Otsu, "A threshold selection method from gray-level histograms", IEEE Trans. Systems Man and Cybernetics, vol. 9, no. 1, Jan. 1979, pp. 62-66.

[17] P. Soille, Morphological Image Analysis: Principles and Applications, 2nd ed., NY: Springer-Verlag, 2002.

[18] S. Essafi, R. Doughri, S. M'Hiri, K.B. Romdhane, and F. Ghorbel, "Segmentation and classification of breast cancer cells in histological images," in The 2nd Information and Communication Technologies, vol. 1, 2006, pp. 1097-1102.

[19] F. Mayer, "Topographic distance and watershed lines," Signal Processing, vol. 38, no. 1, July 1994, pp. 113-125.

[20] Q. Chen, X. Yang, and E. M. Petriu, "Watershed segmentation for binary images with difference transforms," in The 3rd IEEE Haptic, Audio and Visual Environments and Their Applications, 2-3 Oct. 2004, pp. 111-116.

[21] MathWorks, Image Processing ToolboxTM 6 User's Guide, MA: The MathWorks, Inc., 2007.

C. Primkhajeepong was born in Suratthani, Thailand. He received the B. Eng. degrees in electrical engineering from Prince of Songkla University in 2007. He is currently a graduate student of electrical engineering at Prince of Songkla University. His research interests are medical image processing.

P. Phukpattaranont was born in Songkla, Thailand. He received the B. Eng. and M. Eng. degrees in electrical engineering from Prince of Songkla University in 1993 and 1997, respectively, the Ph.D. degree in electrical engineering from the University of Minnesota, in 2004. He is currently an assistant professor of electrical engineering at Prince of Songkla University. His research interests are ultrasound contrast imaging, ultrasound signal processing, medical image processing, and biomedical signal processing. Dr.Phukpattaranont is a member of the IEEE.

S. Limsiroratana was born in Thailand. He received the B.Eng. degree in electrical engineering from Prince of Songkla University in 1991, the M.Arg and Dr.Arg degrees from division of environmental science and technology, Kyoto University in 2000 and 2005 respectively for the detection of fruits on natural background research. He has been working at Department of Computer Engineering, Prince of Songkla University since 1991. His research interests are agricultural image processing, medical image processing, digital watermarking and $\mathrm{AI}$.

P. Boonyaphiphat was born in Thailand. She received the B.Sc. degree from Faculty of Nursing, Prince of Songkla University, in 1980, the M.Sc. degree from Faculty of Science, Mahidol University, in 1986. She has been working at Department of Pathology, Faculty of Medicine, Prince of Songkla University since 1986 . Her position is an assistant professor in anatomical pathology. Her research field is head and neck cancer, breast cancer and image analyzer for histopathology.

K. Kayasut was born in Phuket, Thailand. She received the Medical diploma from Prince of Songkla University in 1996, the Diploma Thai Board of Anatomical Pathology from Mahidol University in 2001 and the Attestation for hematopathology (Attestation de Formation Specialis \&eacute;e Approfondie en Anatomie et Cytologie Pathologiques) from HOTEL-DIEU, Paris 5 University, Paris, France in 2005. She has been working at Department of Pathology, Faculty of Medicine, Prince of Songkla University since 2001. Her position is an assistant professor in anatomical pathology. Her research field is hematopathology. 